\title{
Evaluation of Leech Therapy in Flap Venous Congestion
}

\author{
* Corresponding Author: \\ Aya Elsayed Zidan \\ dr.ayazidan14191@gmail.com
}

Aya Elsayed Zidan ${ }^{1, *}$ MSc., Mohamed Awad Almarakby ${ }^{1}$ MD., Ayman Altramsy ${ }^{1}$ MD., Asmaa Dahy ${ }^{1}$ MD.

Received for publication August 05, 2021; Accepted September 16, 2021; Published online September 16, 2021.

Copyright The Authors published by Al-Azhar University, Faculty of Medicine, Cairo, Egypt. Users have the right to read, download, copy, distribute, print, search, or link to the full texts of articles under the following conditions: Creative Commons Attribution-Share Alike 4.0 International Public License (CC $B Y-S A$ 4.0)

doi: $10.21608 /$ aimj.2021.88110.1540

${ }^{1}$ Department of Plastic and Reconstructive Surgery, Faculty of Medicine for Girls, Al- Azhar University, Cairo, Egypt.

\begin{abstract}
Background: One of the common problems in flap surgery is venous congestion. The literature contains a plethora of alternative procedures to surgical revision for dealing with this issue. The leech therapy is one of these procedures. In the present study, leech therapy was used for the treatment of twenty cases with venous congested flaps. The technique, results and complications will be presented and discussed.

Objective: The aim of this study is to spotlight on the efficacy of leech therapy in salvage of venous congested flaps.

Patients and Methods: A prospective clinical study was carried out on 20 patients with post-operative venous congested fascio-cutaneous flaps. These patients were treated by leech therapy at Al-Zahraa University Hospital and Al-Mataria Teaching Hospital during the period between May 2020 and April 2021.

Results: The percentage of congested areas in the flaps before leech therapy was ranged between $10 \%$ and $100 \%$. The final outcomes of these congested flaps after leech therapy were dramatic regarding improvement in venous congestion and subsequently flap survival. The flap survival rate was ranged between $60 \%$ and $100 \%$ with a mean of $88.25 \%$.

Conclusion: The use of leech therapy has proved its efficacy in significantly relieving flap venous congestion and subsequently increases flap survival rate. Leech therapy should be started as early as possible after other means of venous outflow establishment are exhausted. Guidelines should be strictly fulfilled to avoid biohazards of leech therapy.
\end{abstract}

Keywords: Leech Therapy; Congested; Flaps.

Disclosure: The authors have no financial interest to declare in relation to the content of this article. The Article Processing Charge was paid for by the authors.

Authorship: All authors have a substantial contribution to the article.

\section{INTRODUCTION}

One of the common problems in flap surgery is venous congestion. The literature contains a plethora of alternative procedures to surgical revision for dealing with this issue. Leech therapy is one of these procedures. When all other options for venous outflow establishment have been exhausted, this treatment should be used as a last resort whether the venous compromise was due to mechanical or iatrogenic causes. Leeches are parasitic invertebrates that live in fresh water and are members of the phylum Annelida. ${ }^{1}$ The Food and Drug Administration (FDA) approved leeches as a medical tool in the field of plastic and reconstructive surgery in July 2004 for assisting venous drainage of congested tissues like flaps. ${ }^{8}$ There are over 100 bioactive substances in the saliva of the Hirudo Medicinalis leech, including coagulation inhibitors, platelet aggregation inhibitors, vasodilators, anaesthetizing agents, antimicrobial agents, and anti-inflammatory agents. Hirudin is the most important ingredient which is a highly effective anti-coagulant compound ${ }^{6}$ As a result of the fact that the tyrosine residue of hirudin is not sulfated, it is the most potent naturally occurring specific inhibitor of thrombin available. Therefore, hirudin is more efficient than heparin. ${ }^{9}$

The aim of this study is to spotlight on the efficacy of leech therapy in salvage of venous congested flaps.

\section{PATIENTS AND METHODS}

A prospective clinical study was carried out on 20 patients with post-operative venous congested fascio-cutaneous flaps, treated by leech therapy at Al-Zahraa University Hospital and Al- Mataria Teaching Hospital during the period between May 2020 and April 2021.

Inclusion Criteria: All patients with venous congested flaps regardless their age or gender.

Exclusion Criteria: Patients with blood coagulopathy or receiving anticoagulant, anemia, hypotension, immunosuppressed patients and Patients refusing leech therapy.

Ethical consideration: An informed consent was taken from all patients who agreed to participate in this study after explanation the details of the procedure. 
Methods: All the participants were subjected to the following:

Full history taking including time of the previous operation \&duration of flap venous congestion. Full clinical examination generally \& locally. Hematological evaluation: $\mathrm{CBC}$ and Partial Thromboplastin time were performed every 4 hours.

N.B: Patients receives blood transfusion when their $\mathrm{Hb}$ level is lower than $8 \mathrm{~g} / \mathrm{dl}$.

\section{Steps of the procedure:}

Flap monitoring was done before and after each treatment session clinically and with medical photography.

All patients received prophylactic antibiotic (levofloxacin) for the aeromonas hydrophila bacteria, which are symbionts of leeches to avoid any complications.

Before application, leeches were thoroughly rinsed with deionized water and the congested areas were cleaned with sterile distilled water and cleaned from any antiseptic or antibiotic cream.

A plastic adhesive membrane or a thick layer of gauze was applied around the leech(es) to prevent detached leeches from attaching themselves to other areas as under the flap, fall inside the dressing or on the bed.

The flap was then pricked with a needle and the leech was applied with their mouth opening directed to the congested area. The duration of each leech therapy session was recorded and sessions were repeated every 4 hours (Fig. 1-2-3).

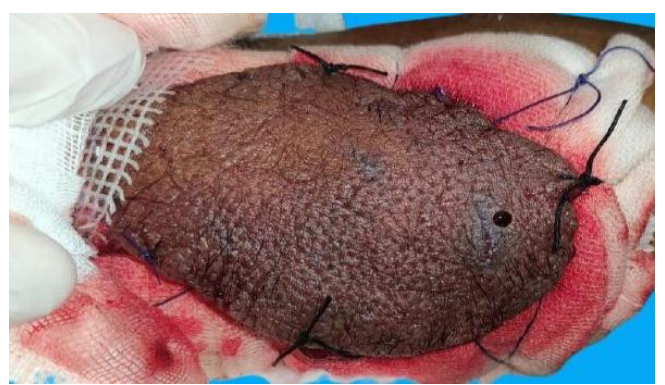

Fig. 1: Congested posterior interosseous atery flap just before initiation of leech therapy.

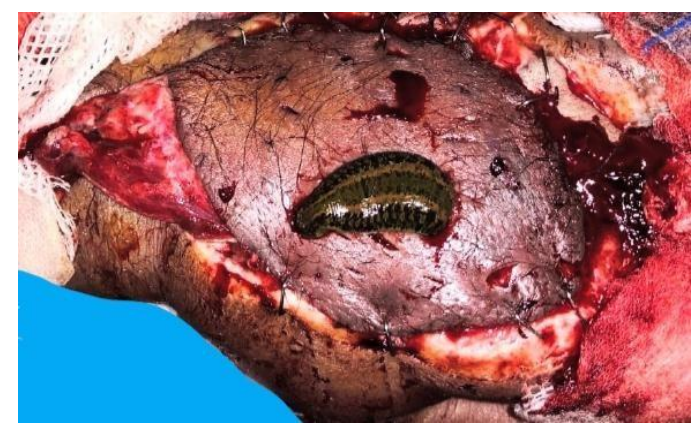

Fig. 2: The pricked congested posterior

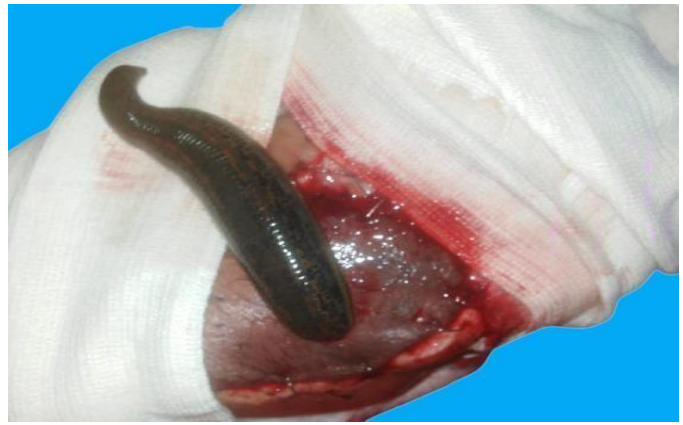

interosseous artery flap with Hirudo Medicinalis just applied.

Fig. 3: The congested posterior interosseous artery flap during the leech therapy session showing Hirudo Medicinalis swelling up after the blood meal.

The decision to discontinue the leeches was made according to the clinical response for the treatment (Fig.4-5-6-7).



Fig. 4: The posterior interosseous artery flap at the $2^{\text {nd }}$ day of leech therapy showing less congestion with less violaceos color.

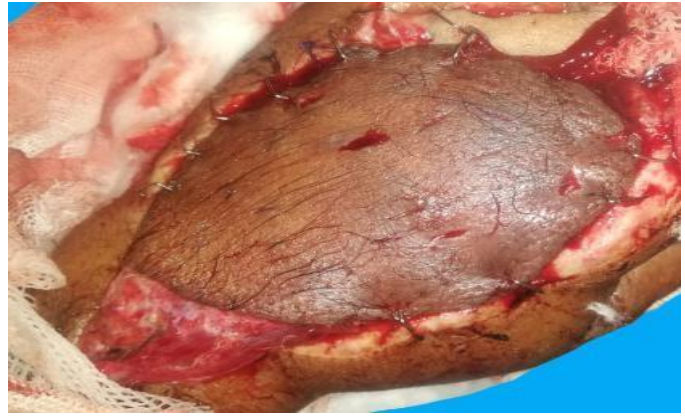

Fig. 5: The posterior interosseous artery flap at the 3rd day of leech therapy showing less congestion with less violaceous color and brighter blood from the pricks. 


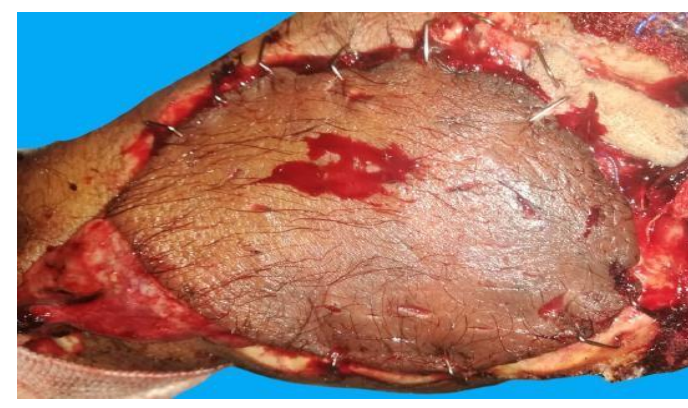

Fig. 6: The posterior interosseous artery flap at the 4th day of leech therapy showing less congestion with less violaceous color and brighter blood from the pricks.

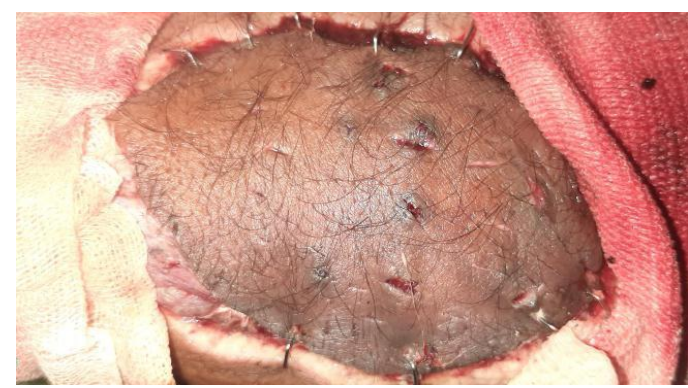

Fig. 7: The posterior interosseous artery flap after the end of leech therapy sessions with almost normal capillary refill time.

Finally, the used leeches were sacrificed after each session in ethanol solution and should not be stored with unused ones to prevent crosscontamination.

\section{Parameters of Assessment:}

Duration and percentage of flap congestion before the start of leech therapy.

Number of leeches used in each session, frequency of sessions and total duration of leech therapy. The final outcome was estimated by the percentage of flap survival through the color of the flap and capillary refill.

\section{RESULTS}

This prospective clinical study was conducted on 20 patients (16 males (80\%) and 4 females (20\%) treated by leech therapy at Al-Zahraa University Hospital and Al-Mataria Teaching Hospital. Their ages ranged between 10 and 50 years with a mean of $30.9 \pm 11.7$ years.

As regard the starting time for leech therapy after flap congestion, it was in the 1st day of congestion in 9 patients $(45 \%)$, in the 2 nd day of congestion in 9 patients (45\%) and in the 3rd day of congestion in 2 patients (10\%) with a mean of (1.65 day) as shown in table (1).
Plastic Surgery

\begin{tabular}{|l|l|c|c|}
\hline \multicolumn{2}{|c|}{} & \multicolumn{3}{|c|}{$\begin{array}{c}\text { Studied patients } \\
(\mathbf{N}=\mathbf{2 0})\end{array}$} \\
\hline \multirow{2}{*}{$\begin{array}{l}\text { The starting day for } \\
\text { leech therapy after } \\
\text { flap } \begin{array}{c}\text { congestion } \\
\text { (mean 1.65 day). }\end{array}\end{array}$} & $\mathbf{1}^{\text {st }}$ day of congestion & 9 & $45 \%$ \\
\cline { 2 - 4 } & $\mathbf{2}^{\text {nd }}$ day of congestion & 9 & $45 \%$ \\
\cline { 2 - 4 } & $\mathbf{3}^{\text {rd }}$ day of congestion & 2 & $10 \%$ \\
\hline
\end{tabular}

Table 1: The starting day for leech therapy in all studied patients.

For the Number of leeches used in each session, 1 leech was used in 8 patients $(40 \%)$, 2leeches were used in 8 patients $(40 \%)$ and 3 leeches were used in 4 patients (20\%) with a mean of 1.8 leech per session as shown in table (2).

\begin{tabular}{|l|l|c|c|}
\hline \multicolumn{2}{|c|}{} & \multicolumn{2}{|c|}{ Studied patients $(\mathbf{N}=\mathbf{2 0})$} \\
\hline $\begin{array}{l}\text { Number of leeches } \\
\text { used in each session } \\
\text { (mean } \\
\text { leeches/session). }\end{array}$ & 1 leech & 8 & $40 \%$ \\
\cline { 2 - 4 } & 2 leeches & 8 & $40 \%$ \\
\cline { 2 - 4 } & 3 leeches & 4 & $20 \%$ \\
\hline
\end{tabular}

Table 2: Number of leeches used in each session for all studied patients.

Regarding the duration of each leech therapy session, it was ranged from 30 to 60 minutes with a mean of 45 minutes and sessions were repeated every 4 hours. The passive oozing of blood through bite wounds after leech removal was ranger between 30 to $60 \mathrm{ml}$ blood (mean $40 \mathrm{ml}$.).

As regard the total period of leech therapy in our study, Leech therapy was used for 3 days in 1 patient (5\%), 4 days in 1 patient (5\%) and 5 days in 18 patients $(90 \%)$ with a mean of (4.85 days) as shown in table (3).

\begin{tabular}{|l|c|c|c|}
\hline \multicolumn{2}{|c|}{} & \multicolumn{2}{|c|}{$\begin{array}{c}\text { Studied patients } \\
(\mathbf{N}=\mathbf{2 0})\end{array}$} \\
\hline \multirow{2}{*}{$\begin{array}{l}\text { Total period of } \\
\text { leech } \begin{array}{c}\text { therapy } \\
\text { (mean 4.85 days). }\end{array}\end{array}$} & $\mathbf{3}$ days & 1 & $5 \%$ \\
\cline { 2 - 4 } & $\mathbf{4}$ days & 1 & $5 \%$ \\
\hline
\end{tabular}

Table 3: Total period of leech therapy in all studied patients .

Regarding the final outcome of congested flaps after leech therapy in all studied patients, it was $100 \%$ survival in 7 patients (35\%), 95\% survival in 1 patient (5\%), $90 \%$ survival in 5 patients $(25 \%)$, $80 \%$ survival in 4 patients $(20 \%), 70 \%$ survival in 2 patients $(10 \%)$ and $60 \%$ survival in 1 patient $(5 \%)$ with a mean survival rate $(88.25 \%)$ as shown in table (4). 


\begin{tabular}{|l|l|c|c|}
\hline \multicolumn{2}{|c|}{} & \multicolumn{2}{|c|}{$\begin{array}{c}\text { Studied patients } \\
(\mathbf{N}=\mathbf{2 0})\end{array}$} \\
\hline \multirow{2}{*}{\begin{tabular}{l} 
The $\begin{array}{l}\text { Outcome } \\
\text { (mean survival } \\
\text { rate 88.25\%). }\end{array}$ \\
\cline { 2 - 4 }
\end{tabular}} & $\mathbf{1 0 0 \% \text { survival }}$ & 7 & $35 \%$ \\
\cline { 2 - 4 } & $\mathbf{9 5 \%}$ survival & 1 & $5 \%$ \\
\cline { 2 - 4 } & $\mathbf{9 0 \%}$ survival & 5 & $25 \%$ \\
\cline { 2 - 4 } & $\mathbf{8 0 \%}$ survival & 4 & $20 \%$ \\
\cline { 2 - 4 } & $\mathbf{7 0 \%}$ survival & 2 & $10 \%$ \\
\hline
\end{tabular}

Table 4: The final outcome in all studied cases.

There were no cases under the study showed no response to leech therapy. At least $60 \%$ to $100 \%$ improvement in congestion and subsequently the mean flap survival rate was $88.25 \%$.

The results of leech therapy in dealing with congested flaps are presented in figures (8-9-10$11)$.

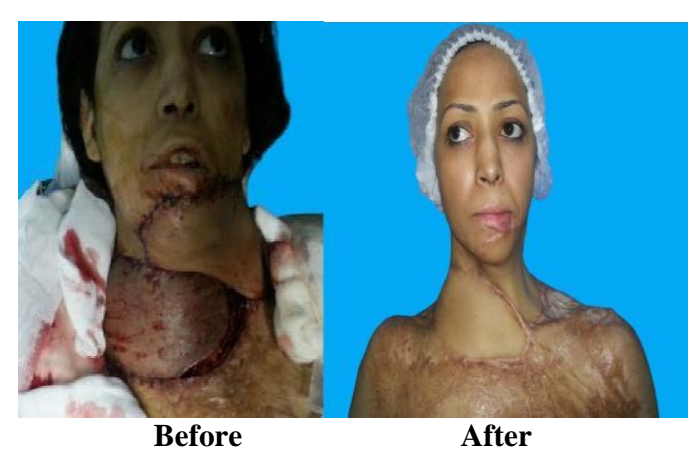

Fig. 8: Female patient 30 years old with $100 \%$ congested Rt supraclavicular artery perforator flap one day after surgery (before). After leech therapy, there is $100 \%$ survival of the flap.

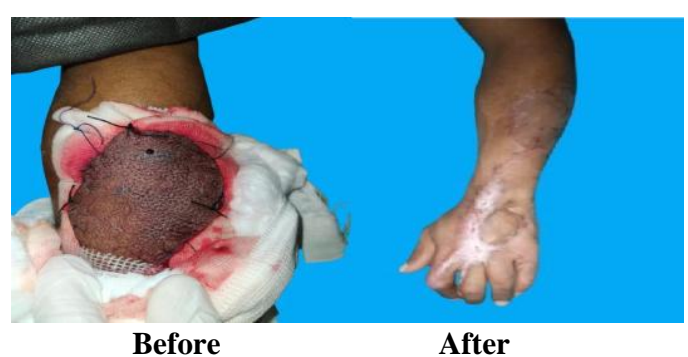

Fig. 9: Male patient 40 years old with congested posterior interosseus artery flap (before). After leech therapy, there is $60 \%$ survival of the flap.

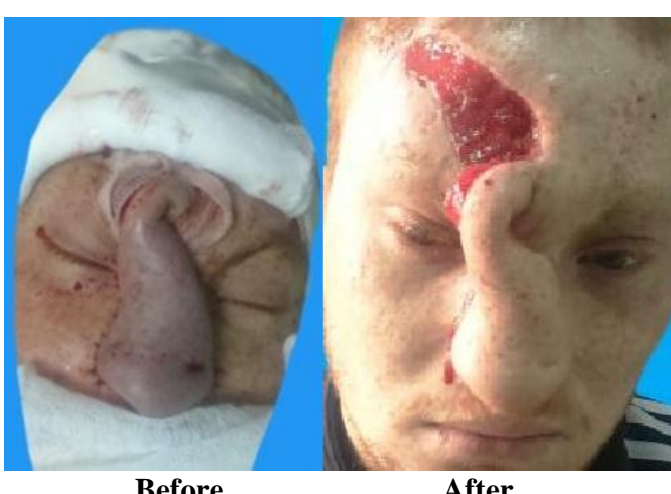

Fig. 10: Male patient 25 years old with preexpanded $100 \%$ congested forehead flap (before). After leech therapy, there is $100 \%$ of congestion relief and total flap survival.

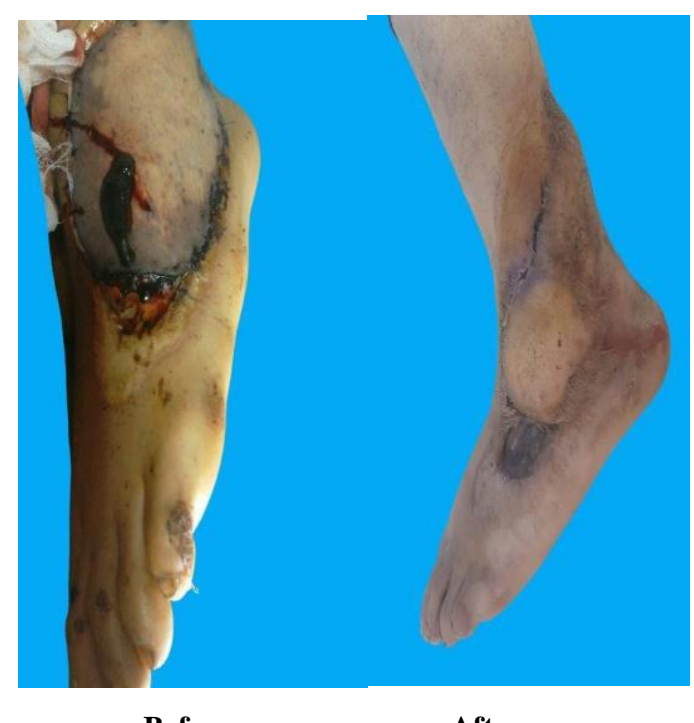

Before

After

Fig. 11: Male patient 32 years old with $30 \%$ congested reversed sural artery flap. After leech therapy, there is $80 \%$ survival of the flap.

\section{DISCUSSION}

Flap venous congestion can be distinguished by the dusky purple color of the flap tissues. For example, medicinal leeches are applied to congested flaps where surgical microvascular revision has failed in order to treat this condition and temporarily restore blood perfusion within the flap for a limited time period. ${ }^{2}$

Leech therapy works by simultaneously lowering tissue capillary pressure and increasing local anticoagulation via three distinct mechanisms: active suction, secretion of vasoactive substances such as hirudin, and passive blood oozing through bite wounds following leech removal. ${ }^{5}$

Within 30 to 90 minutes, each applied leech can expect to consume 5 to $15 \mathrm{~mL}$ of blood during a feeding session, and each wound can be expected to ooze extra 50 to $150 \mathrm{~mL}$ of blood over the course of a 24-hour period. ${ }^{10-11}$ In our study, the passive oozing of blood through bite wounds after leech removal was ranged between 30 to $60 \mathrm{ml}$ 
(mean $40 \mathrm{ml}$.) and the duration of each leech therapy session was ranged from 30 to 60 minutes with a mean of 45 minutes.

As regards the starting day, number of leeches used in each session and total sessions of leech, in our study, leech therapy was started in an average of 1.65 days following surgical interventions or trauma. In average, 1.8 leeches were applied to the congested flap with a mean of 7 treatment sessions per patient. The total survival rate was $88.25 \%$ and this corelates with the controlled study done by Riede et al. ${ }^{7}$ on 23 patients with congested skin flaps and hematomas. Following surgical interventions, leech therapy was initiated on average 2.6 days after the procedure. It was found that on average, 2.6 leeches were applied to patients' wounds, and that each patient received an average of 1.7 treatment sessions. According to the authors, 87 percent of these patients $(20 / 23)$ had restitution and integration of their skin flaps after undergoing the procedure. After an average of 1.1 days, clinical improvement could be observed.

Regarding the efficacy of leech therapy in dealing with congested flaps, in our study, there is high rate of success in relieving congestion and flap survival. The mean survival rate was $88.25 \%$ in the 20 cases under the study, while Cornejo et $a^{4}{ }^{4}$ showed a slightly lower rate of salvage (about $60.9 \%$ ), considering success as there was no flap loss or partial flap loss requiring further reconstructive procedures. On the other hand, Whitaker et al. ${ }^{12}$ showed that medical leeches salvaged the reconstructed congested flaps in 216 of the 279 cases $(77.4 \%)$ and in congested free flaps, it salvaged 61 of 74 cases $(82.4 \%)$.

Regarding the need for blood transfusion during leech therapy, in our study, there was no need for blood transfusion as the lowest hemoglobin level was 9.2 g., while Chepeha et al. $^{3}$ transfused blood to 6 out of 108 cases treated with leech therapy.

\section{CONCLUSION}

The use of leech therapy has proved its efficacy in significantly relieving flap venous congestion and subsequently increases flap survival rate. Leech therapy should be started as early as possible after other means of venous outflow establishment are exhausted. Guidelines should be strictly fulfilled to avoid biohazards of leech therapy.

\section{REFERENCES}

1. Boissiere F, Gandolfi S, Riot S, et al.: Plastic and Reconstructive Surgery - Global Open 2021; 9 (1): e3327.
2. Butt. Ahsan, Ismail A, Lawson-Smith L, et al.: Leech Therapy For The Treatment Of Venous Congestion In Flaps, Digital RePlants And Revascularizations - A TwoYear Review From A Regional Centre. Journal of Ayub Medical College, Abbottabad 2016; 28 (2): 219-23.

3. Chepeha, Nussenbaum, Bradford, et al.: Leech Therapy for Patients With Surgically Unsalvageable Venous Obstruction After Revascularized Free Tissue Transfer, Arch Otolaryngol Head Neck Surg. 2002; 128 (8): 960-5. doi:10.1001/archotol.128.8.960.

4. Cornejo A, Shammas RL, Poveromo LP, et al.: Institutional outcomes of leech therapy for venous congestion in 87 patients. $J$ Reconstr Microsurg.2017; 33(9): 612-8.

5. Hackenberger PN and Janis JE: A Comprehensive Review of Medicinal Leeches in Plastic and Reconstructive Surgery. Plastic and Reconstructive Surgery-Global Open 2019; 7(12): e2555.

6. Lui, Celina BSN, MSN, et al.: Medicinal leech therapy, new life for an ancient treatment 2019; 5 (11): 25-30.

7. Riede, Koenen, Goerdt, et al.: Der Einsatz medizinischer Blutegel zur Therapie der venösen Stase und von Hämatomen bei Lappenplastiken, JDDG J der Deutschen Dermatol Gesellschaft 2010, 8: 1-9.

8. Sarvesh KS, Kshira R: Medical leech therapy in biomedicine-Review, Journal of Ayurveda and Integrative Medicine 2018; https://doi.org/10.1016/j. jaim 2018.09.003.

9. Sayed AM, Mariyam G, Sayed JM, et al.: Comparison of leeching and heparin therapy in management of active venous congestion of limbs in rats 2016; 2 (3): 2530.

10. Sig AK, Guney M, Uskudar Guclu A, et al.: Medicinal leech therapy-an overall perspective. Integr Med Res 2017; 6 (4): 337-43.

11. Viviano SL, Hahn E, Lee ES, et al.: The leech condo: an innovative approach to containing leeches on a congested flap. Eplasty. 2015; 15: ic21, PMID: 25987944.

12. Whitaker IS, Oboumarzouk O, Rozen WM, et al.: The efficacy of medicinal leeches in plastic and reconstructive surgery: a systematic review of 277 reported clinical cases. Microsurgery 2012; 32 (3):240-50. 